\title{
Autoritarismo y terremoto
}

Luis Alvarenga

\section{Introducción}

Las élites salvadoreñas han manejado el discurso de la modernización para legitimar una serie de cambios operados en las estructuras socioeconómicas del país. De hecho, estas élites han sobresalido por su dinamismo en comparación a los demás grupos dominantes en Centroamérica. Después de la firma de los Acuerdos de Paz, en 1992, los distintos gobiernos de ARENA han dado cuerpo a su proyecto de modemización: la privatización de algunos sectores del aparato estatal - telecomunicaciones y electricidad-, fue uno de los primeros pasos. Las élites gobernantes legitimaron la privatización enmarcándola dentro de un conjunto de reformas destinadas — según ellos-a hacer más eficiente al Estado.

El empuje transformador incluyó también a su instrumento político: subieron a la dirección del partido ARENA caras nuevas, no tan relacionadas con el pasado que ha marcado a la agrupación oficialista. La cúpula empresarial ha mostrado ser emprendedora. Colocó en el mercado salvadoreño los más interesantes adelantos en las telecomunicaciones y ha atraído la inversión de consorcios transnacionales. El sector bancario ha tenido también lo suyo: Bancos como el Cuscatlán — cuyo socio fundador es el ex Presidente Alfredo Cristiani- sc han posicionado entre los más poderosos en el ámbito latinoamericano. Los éxitos en el ámbito macroeconómico se sucedían uno a uno. Para fin de siglo, todo hacía ver que la modernización era algo más que palabras.

Todo eso cambió en enero de 2()()1: Un terremoto de gran magnitud resquebrajó la fachada de modernidad e hizo ver cuál es el verdadero país en el que también habitan esas élites. La dinámica de intercambio comercial puede haberse modernizado - en favor de unos cuantos-, pero El Salvador está lejos de haber ingresado a la modernidad en términos sociales y políticos. La modernización ha sido un autobús en el que sólo los que pueden pagar holetos de primera 
clase pueden viajar. Los orros salvadoreños y salvadoreñas viven en un país que los felices pasajeros del autobús no pueden ni quieren ver, embriagados por el vértigo de su propia ilusión modernizadora. Esos otros pagan la peor parte del boleto de viaje: viven las expresiones de una cultura autoritaria, que sostiene la alucinación de modernidad de las élites.

¿Por qué hablamos de autoritarismo? Porque una cosa puede ser el discurso democrático que maneja el Estado salvadoreño y otra, las prácticas autoritarias que están profundamente enraizadas en nuestro sistema político. Franz Neumann, en su estudio sobre los Estados autoritarios', anota una serie de elementos que caracterizan a las dictaduras totalitarias. Veamos.

En primer lugar, los totalitarismos modernos declinan la autoridad basada en el Derecho a favor de un sistema de control policial. Además, y muy importante, es el aparecimiento de un "partido estatal monopolizador", definido como "un instrumento flexible que proporciona la fuerza para controlar la maquinaria del Estado y la sociedad y para cumplir la tarea gigantesca de aglutinar los elementos autoritarios que ésta contiene"'?

En toda sociedad autoritaria, el partido monopolizador asegura el control del Estado, apelando a los siguientes recursos: Un liderazgo vertical; la sincronización de las organizaciones sociales "no sólo para controlarlas, sino para ponerlas al servicio del Estado; "la creación de élites jerarquizadas, de modo que permita a los gobernantes controlar a las masas desde adentro y disfrazar la manipulación desde fuera, esto es, ayudar a las burocracias en el sentido limitado del término mediante grupos de liderazgo privados, dentro de los diversos estratos de la población"’.3; el aislamiento del individuo; la transformación de la cultura en propaganda y, último pero no menos importante, "la confianza en el terror, es decir, en el uso de la violencia no calculable, como amenaza permanente contra el individuo".

Las caracterizaciones de la ciencia deben tomarse solamente como instrumentos para entender la realidad y no como guiones a los cuales esta realidad debe adecuarse forzadamente. Lo decimos porque, si bien el Estado salvadoreño no reúne todos los elementos que Neumann incluye para caracterizar a las dictaduras, este Estado presenta muchas tendencias autoritarias. No hay, por ejemplo, ese férreo control sobre los individuos, ese estado de sitio permanente que caracteriza a las dictaduras típicas. Tampoco hay una intromisión directa en las artes

1. Ncumann, Franz: El Estado democrático y el Estado autoritario. Compilación y prefacio de H. Marcusc. Paidós, Bucnos Aircs, s/f.

2. Ibid, pp. 229-230.

3. İdem.

4. Ídcm. 
o en la producción intelectual para convertirlas en apologías del régimen. Pero sí hay otros rasgos que coinciden con la tipificación de autorilarismo. Por ejemplo, el papel del partido oficial. Éste controla las estructuras estatales, quizás ahora de una forma menos patente que en el pasado. Sin embargo, hay que decir que, salvo excepciones, la dirección de las distintas estructuras estatales corre a cargo de miembros de la cúpula partidaria.

También está el verticalismo. Ciertamente, las reformas dadas a partir de 1992 han roto de alguna forma el monopolio absoluto de las decisiones políticas, pero, básicamente, el partido-Estado impone su voluntad sin consultas a la ciudadanía. Claro, hay procesos de negociación que deben implementarse para poner en marcha alguna medida determinada, pero lo cierto es que el poder existente en el Ejecutivo y en la Asamblea no dialoga con los ciudadanos.

Está, finalmente, el papel de las élites, que conforman grupos de poder que, a su vez, facilitan el dominio del partido-Estado. Las élites dominan aspectos importantes de la vida ciudadana: medios de comunicación, ciertos gremios, elcétera. Las élites están representadas en el partido-Estado, pero también en distintos ámbitos de la actividad civil. Debe admitirse, empero, que el partido-Estado no representa a todas las élites salvadoreñas. Se han observado reacciones, que van desde las críticas moderadas hasta las abiertas discrepancias entre sectores de poder económico con las polílicas del partido-Estado.

Hechas estas apreciaciones previas, pasemos a dilucidar cuál es el comportamiento del Estado autoritario ante la catástrofe nacional. También queremos poner a prueba este planteamiento: Los terremotos del 13 de enero y el ocurrido exactamente un mes después, demostraron que no es viable cualquier proyecto modernizador que se base en el autoritarismo y en la exclusión. Eso fue lo que se puso de relieve con la catástrofe. Tomaremos un caso emblemático, para demostrar lo que planteamos: el alud de tierra que sepultó un barrio de clase media en Santa Tecla.

\section{Las Colinas: un largo camino que llevó al desastre}

Lo ocurrido a la Residencial Las Colinas fue la muestra de cómo la intervención humana puede agrandar las repercusiones de los fenómenos naturales. En un interesante ensayo titulado Terremolos, urbanización y riesgo sísmico en San Salvador (Revista Prisma, No. 18, julio-agosto 1996), el ingeniero civil Julian Bommer establecía una distinción que es importante tener presente. Cilando a Fournier d'Albe, Bommer recordaba que, en materia de riesgos sísmicos, siempre entran en juego los elementos naturales y las acciones humanas. La distinción establecida es la siguiente: Una cosa es la peligrosidad sísmica, en tanto que fenómeno natural, y otra, la vulnerabilidad, "que refleja más bien las características de la intervención humana". Cuando se habla de peligrosidad, se está hablando de "características de la naturaleza que no pueden ser modificadas". 
Distinto ocurre con el término vulnerabilidad. El autor lo define como la "capacidad de resistencia de las estructuras expuestas a estos movimientos". En base lo anterior, podemos sacar una conclusión digna de Perogrullo: no se puede hacer nada contra la peligrosidad de un terremoto, pero sí se puede hacer mucho para disminuir la vulnerabilidad de las estructuras arquitectónicas, y, por tanto, para minimizar los costos humanos que toda calástrofe de origen sísmico genera.

En su ensayo, Bommer enuncia una serie de requerimientos que la planificación arquitectónica debería tomar en cuenta para reducir el margen de vulnerabilidad. El autor hace mención de estudios de suelo - considera una imprudencia, por ejemplo, construir sobre tierra blanca, dado el menor grado de compactación que esta presenta con respecto a la tierra negra-y la elaboración de diseños arquitectónicos adecuados. También alude a la necesidad de reparar y reforzar adecuadamente las estructuras dañadas por sismos anteriores. En países como Nueva Zelanda, o como el estado norteamericano de Califomia, recordaba, existe una normativa que regula de manera estricta la construcción de estructuras resistentes a los sismos. En breves palabras, el grado de vulnerabilidad podría disminuirse si se cumple con una serie de estándares de construcción y de planificación arquitectónica. Lógicamente, al Estado le corresponde velar por el cumplimiento de estos requisitos. ¿Cuál fue el papel de ese Estado con respecto a lo ocurrido en Las Colinas?

El desastre de Las Colinas expresa cómo la falta de medidas para reducir la vulnerabilidad puede tener graves consecuencias. La desaparecida residencial estaba ubicada en la Cordillera del Bálsamo. Hay que remontarse a febrero de 1998 para comprender que esto no se trata de un caso aislado. En el citado mes, la Alcaldía de Nueva San Salvador emitió una ordenanza prohibiéndole a una compañía constructora iniciar obras en la Cordillera del Bálsamo. El gobierno municipal estableció sanciones para quienes infringieran la ordenanza. El argumento era el siguiente: la Cordillera del Bálsamo es una zona de recarga de mantos acuíferos, por lo tanto, hay que establecer medidas para protegerla. La Cordillera también es el hábitat de variadas especies animales y vegetales.

Esto generó una agria controversia en la que intervinieron, por una parte, la Alcaldía de Nueva San Salvador, organizaciones comunitarias y grupos ecologistas y, por otra, empresarios de la construcción y el gobierno salvadoreño. La presidenta de la Cámara Salvadoreña de la Construcción, CASALCO, Patricia Lazo de Parras, afirmó que lo primero que había que garantizar era "el respeto al uso de la propiedad", al cual elevó a la categoría de "derecho fundamental" consagrado por la Carta Magna. Esto llegó más allá. La constructora que había comenzado a trabajar en la Cordillera demandó a la Alcaldía. A resultas del juicio, ésta última fue condenada a pagarle una indemnización por los "perjuicios" causados a sus ventas e imagen.

Más adelante, se dio otro episodio. En el municipio de Nuevo Cuscatlán, la constructora Trafalgar, comenzó a talar árboles en la finca San Antonio La Joya 
para iniciar obras de construcción. Cuando los vecinos crearon un comité ecológico para proteger la zona, se dieron cuenta de algo muy grave: La tala de los árboles estaba completamente legalizada. La empresa Trafalgar operaba dentro de la legalidad: contaba con una autorización del Viceministerio de Vivienda y de la Alcaldía Municipal. Esto tenía una explicación: el socio mayoritario de la constructora se llamaba Hans Bodewig, a la sazón Viceministro de Vivienda.

El Comité de Nuevo Cuscatlán, respaldado por la entidad ecológica CESTA, inició un proceso legal en contra del funcionario. La disputa, que culminó con una sanción jurídica en perjuicio de Bodewig, tuvo un episodio que sólo recuerda las prácticas represivas del pasado. El mismo día en que el Comité solicitó la intervención de la Asamblea Legislativa en el caso, el presidente del Comité, Antonio Méndez, fue amenazado de muerte. Días después, sufrió un atentado, del cual salió ileso.

El asunto no concluyó con las fianzas que se le impusieron a Bodewig. Al darse el cambio de gobierno en 1999, entró al frente del Ministerio de Medio Ambiente Ana María Majano, en reemplazo de Miguel Araujo. Majano aprobó el proyecto de urbanización en Nuevo Cuscatlán. Eso dio luz verde a las construcciones en toda la zona de la Cordillera y echó al traste las recomendaciones de los ecologistas. Se comenzó a construir, sin atender a esas consideraciones, pero también —y el caso de Las Colinas lo demuestra- sin seguir normas que garantizaran un mínimo nivel de vulnerabilidad.

\subsection{Enseñanzas de una tragedia}

Uno de los problemas fundamentales que se debate en el terreno de la filosofía política es el papel del Estado. Simplificando extremadamente las cosas, habría que decir que se trata de un debate entre dos posiciones extremas (y una serie de intermedias): Entre quienes postulan la existencia de un Estado omnímodo, que regule todas las esferas de la vida ciudadana -incluso, que hasta tenga injerencia en las relaciones individuales- y entre aquellos que abogan, si no por la destrucción del aparato estatal, pero sí por un Estado cuyas funciones estén reducidas al mínimo.

Las élites salvadoreñas utilizan el discurso neoliberal. En el campo de la filosofía política, el neoliberalismo concibe un Estado reducido, que se limite a facilitar las condiciones que garanticen la libre competencia y la iniciativa privada. Los neoliberales se proclaman herederos de la tradición de pensamiento inaugurada por Adam Smith. Es ilustrativa la síntesis que la profesora estadounidense Helen Buss Mitchell hace sobre el pensamiento económico de Smith y sus consecuencias: "La teoría de Smith afirmaba que los individuos deberían de dejarse solos (...) para ir en pos del capitalismo de libre empresa. Sin regulación gubernamental, Smith creía, las fuerzas del mercado de la oferta y la demanda

Autoritarismo y terremoto 
regularían la economía, y la compelencia mantendría dentro de un rango razonable los precios"s.

Si observamos bien lo que hemos afirmado en el párrafo anterior, podemos advertir los dos papeles que las élites asignan al Estado. Hay un nivel explícito y un nivel oculto. En el nivel explícito, tenemos un Estado reducido, supuestamente, a la mínima expresión. El Hermano Mayor que temía George Orwell sería un remoto fantasma en el Estado neoliberal. Éste mantendría sus manos fuera de toda esfera privada (comenzando, por supuesto, por el intercambio capitalista). Por el contrario, el aparato estatal se limitaría a administrar algunos bienes de utilidad pública, pero este papel administrador tendería, con el tiempo, a irse disminuyendo, de tal suerte que quizá solamente funciones como la de garantizar la soberanía nacional serían de las pocas que le irían quedando.

El nivel oculto reside en ese laissez faire del Estado. Precisamente, para dejar hacer a las élites, el Estado liene que facilitarles ciertas condiciones. Por eso, hablábamos de un Estado facilitador. Aquí reside una trampa. Un Estado facilitador de la así llamada libre competencia y de la libre iniciativa, supuestamente lo que tiene que hacer es limilarse a poner sus manos fuera del juego. No es esa la realidad en el caso salvadoreño, ni tampoco en el caso concreto de Las Colinas. El Estado, efectivamente, facilitó el dejar-hacer a las empresas constructoras. Pero lo hizo mediante una intervención abierta, que es algo que contraría el discurso neoliberal de las élites.

Como era evidente que las construcciones eran un buen negocio - - casi podría hablarse de una "fiebre del oro" de las constructoras-, el Estado pasó por encima de la legalidad con tal de allanarle el camino a los empresarios de este rubro. $\mathrm{Y}$ puso en juego una serie de prácticas autoritarias para garantizar el supremo derecho a la propiedad. Verbigracia: La Ley de Medio Ambiente demanda una consulta popular con los pobladores de cualquier sitio donde se pretende llevar a cabo obras de construcción. En la Cordillera del Bálsamo, esta exigencia no se respetó. Más bien, se hizo caso omiso de los señalamientos de los ciudadanos, y no se vaciló en poner el aparato estatal a las órdenes de las empresas.

Otra manifestación autoritaria es esta última. El Estado deja de entenderse como un instrumento que garantice los derechos de la ciudadanía y se vuelve un instrumento del poder (económico, polílico y social) de las élites. En 1976, durante el tiempo en que la Reforma Agraria se encontraba en discusión, Ignacio Ellacuría ironizaba sobre este uso del Estado. Es célebre el título del editorial: "A sus órdenes, mi capital”. El Estado autoritario, que en el pasado servía como guar-

5. Cfr. Liberalismo y conservadurismo, en Raices de la sabiduria, México, 1998, p. 394 y ss. 
dia real de las élites terratenientes, ahora actúa como seguridad privada de ciertos grupos empresariales o financieros. $Y$ aunque en los discursos oficiales se hable de "participación” y “democracia”, lo cierto es que El Salvador todavía sigue arrastrando la rémora del autoritarismo.

\section{Una emergencia nacional con soluciones privadas}

Una primera decisión que tomó el mandatario salvadoreño Francisco Flores, a raíz del seísmo del 13 de enero, fue conformar una Comisión Nacional de Solidaridad, CONASOL, única y exclusivamente con empresarios privados. La Comisión se encargaría de manejar la ayuda internacional destinada para el terremoto, sin que el Estado metiera mano. Los argumentos presidenciales eran bastante loables: Al estar conformada por miembros del sector privado, CONASOL actuaría independiente de los vaivenes políticos y manejaría con honestidad el destino de la ayuda de países amigos. No tenemos razones para poner en juicio las buenas intenciones de los miembros de CONASOL. Porque el asunto no se limitaba a intenciones: era un problema de realidades. La Comisión demostró ser insuficiente para cubrir las necesidades de los municipios en estado de emergencia. Tal fue el precio de conservar una tendencia autoritaria: excluir del diálogo a la ciudadanía y manejar las decisiones nacionales siempre al nivel de élites.

El gobierno tuvo que enmendar la plana, ante la enorme presión generada por las denuncias de los afectados por el temblor. La ayuda no llegaba, decían. Era evidente que había que cambiar de esquema. En una movida bastante rápida, el Presidente se dirigió a la nación para anunciar que las municipalidades se encargarían, a partir de ese momento, de distribuir la ayuda internacional. Quizá fue eso lo que debió hacerse desde el principio: enfrentar el problema nacional de la emergencia desde una perspectiva también nacional. Y hablar de este lipo de perspectiva significa que toda la sociedad debe participar en la toma de decisiones sobre su destino.

Esto no implicaba que se habían abierto las puertas a las soluciones tomadas de común acuerdo entre los distintos sectores sociales. Un gesto, bastante gráfico, resume cuál era la actitud gubernamental al respecto. El gesto gráfico es el siguiente: El Presidente apareció ante las cámaras entregando una bolsa llena de dinero a un alcalde. Eso implicaba, hasta cierto punto, desmarcarse de los problemas locales y dejar la administración de las crisis a los gobicrnos municipales. De las decisiones a un ámbito más amplio - verbigracia, el plan de reconstrucción nacional- se encargaría única y exclusivamente el gobierno. Ese era un poco el subtexto. Varias alcaldias, incluyendo muchas del partido oficial, reaccionaron devolviendo la ayuda. No querían limitarse a repartir mil quinientos colones para remover escombros. Demandaban que se les incluyera en la formulación de los planes para emprender la reconstrucción del país. Era un claro rechazo a las prácticas verticalistas de un Estado autoritario.

Autoritarismo y terremoto 
El Alcalde de Santa Tecla, Óscar Ortiz, tuvo que enfrentar el problema de tener una gran concentración de damnificados en los terrenos de una cancha de fútbol. Ortiz demostró habilidad en el manejo de la crisis y se convirtió en vocero de las críticas hacia el deslucido desempeño del gobierno central ante la catástrofe. El Alcalde demostró ser capaz de proponer planes eficientes para enfrentar el problema. Debatió con sus detractores - mayormente allegados al partido en el gobiemo- y salió bien librado. Quizá eso explica lo ocurrido en la visita de la Reina Sofía de España - a quien ciertos sectores llamaron, en tono de pura adulación, "Reina Solidaria"- al municipio de Nueva San Salvador. Una nota publicada en el periódico español El País, por la enviada Margarita Rivière, el 16 de febrero, afirma lo siguiente: "En Santa Tecla, donde el 13 de enero desapareció un barrio entero de 400 casas, con 600 muertos e incontables desaparecidos, (la Reina) pudo ver lo que es un pueblo convertido en cementerio que ha tenido que ser bañado en cal. Escuchó las explicaciones del ministro del Interior y responsable de la criticada Comisión de Emergencia Nacional; fue acompañada por la esposa del presidente, pero no tuvo oportunidad de escuchar lo que ocurrió ese día de primera mano: el alcalde del pueblo, miembro del partido de la oposición y muy crítico con la forma gubernamental de organizar la ayuda humanitaria, no fue invilado".

Esto quiere decir que las voces disonantes no tienen cabida cuando el Estado autoritario quiere conocer otras opiniones. La exigencia de las cincuenta ONG y de la Conferencia Episcopal, en el sentido de crear un plan de reconstrucción nacional basado en el consenso de todos los sectores, es un rechazo a la dinámica excluyente con que se mueve el actual gobierno.

\section{Una oportunidad histórica de enmendar el rumbo}

Las ONG demandaron "que en el plazo más breve posible se presente una sólida propuesta de reconstrucción y desarrollo que nos permita llegar unidos como país a la reunión del Grupo Consultivo de Madrid, que se celebrará en marzo", según reza la citada nola de El Pais. La cita en la capital española es, pues, algo crucial. Es también la oportunidad para que las élites gobernantes cambien su manera de manejar los destinos nacionales.

Para esto, se requiere de seriedad a la hora de encarar el tema de los planes de reconstrucción. Y seriedad implica actuaciones consistentes y críticas, no decisiones erráticas. Un ejemplo patético fue lo que ocurrió en el seno del FMLN. El ex candidato presidencial de esa formación de izquierda, Facundo Guardado, viajó a España con una delegación gubernamental, “a darle las gracias" al gobierno hispano por la ayuda prestada a las víctimas del terremoto. La decisión de Guardado fue, al parecer, fue personal y no la consultó con las instancias partidarias. A su partida, hubo voces que hablaron de hacerle un "juicio político". El FMLN prohibió a sus miembros viajar con delegaciones gubernamenta- 
les, cosa que también habían hecho dos diputados del Parlacen, pero sin el revuelo que armó la partida de Guardado. Antes de que éste volviera, los ánimos se calmaron. No habría sanciones para el ex comandante guerrillero. Más bien, el FMLN pareció recapacitar y seguir el ejemplo de Facundo: El partido de izquierda ha pedido al gobiemo que lo incluyan a la cita de Madrid, a lo que el Presidente Flores se ha mostrado refractario. El hecho de que la antigua coalición de grupos guerrilleros se crea más cerca de la silla presidencial no debe obnubilar los ánimos de sus dirigentes. La oposición política debe acudir a Madrid con el mismo espíritu con que las ONG han demandado la inclusión de todos los sectores sociales en el plan de reconstrucción nacional. En particular, el FMLN debe reivindicar su deuda histórica con aquellos a los que dijo representar durante la guerra. Una forma de hacerlo es cambiar su horizonte - acaparado casi por completo por la próxima contienda presidencial-y dialogar con la ciudadanía, tal como lo ha hecho el alcalde Ortiz.

La cita de Madrid debería ser solamente uno de los tantos pasos a recorrer en la búsqueda de alternativas democráticas para sacar al país de su actual postración. No debería convertirse en un fin en sí mismo, sino en un medio para ensayar prácticas basadas en el diálogo y la inclusión. "La democracia es dolorosa", escribió el poeta Álvaro Darío Lara en un comentario publicado en el periódico Co Latino. Es dolorosa, porque implica renuncias, concesiones, apertura. Implica renunciar al poder omnímodo, a la razón infalible y al ejercicio de la violencia y de la exclusión como medios para zanjar diferendos. Es dolorosa, porque demanda concederle parte de la razón al otro. Es dolorosa también porque se basa en la apertura y el diálogo, y se sabe que una de las tentaciones del poder autoritario es la de monologar, la de escucharse sólo a sí mismo. Pero también es un ejercicio necesario.

Hablar de apertura y diálogo, romper con el monopolio de las decisiones que es lo que sustenta a toda estructura autorilaria - no quiere decir, en este caso, caer en la trampa del consenso. El consenso es un recurso y un discurso. Bajo el recurso del consenso y la concertación, el Estado autoritario ha encontrado un instrumento para legitimar medidas antipopulares. Una concertación entre el partido de gobierno y un pequeño grupo de ex dirigentes de la antigua guerrilla dio como resultado la imposición del IVA a cambio de ganancias políticas. Utilizando el discurso del consenso y de la concertación, se descalifica a las opiniones críticas: los aguafiestas no lienen lugar en la gran unidad nacional bajo las alas protectoras del poder. No se trata, pucs, de consensos, sino de todo lo contrario: de asumir las diferencias de opinión, los intereses contrarios y las posiciones dispares, para fundamentar una verdadera práctica democrálica. Esto implica otro riesgo: Los Estados autoritarios desarrollan sus contravenenos con una agilidad pasmosa y ya se ha vislo cómo hay sociedades donde la apertura democrálica, las libertades políticas y el respeto a la expresión de opiniones contrarias sirven para legitimar el orden de cosas vigente y para no hacer cambios en las

Autoritarismo y terremoto 
esferas sociales y económicas. Hablamos, pues, de modelos autoritarios más desarrollados. El autoritarismo de las élites salvadoreñas es mucho más rudimentario.

Las prácticas autoritarias —que han permeado nuestra cultura, y no son sólo privilegio de los grupos dominante- deben abandonarse, si no queremos que el país se desplome, como las casas de adobe en muchas aldeas pobres del país. Las élites deben comprender que hemos llegado al siglo XXI y que no habrá modernidad que se precie de tal si se continúa ejerciendo el poder como si todavía estuviéramos en el país que se quiso dejar atrás con la firma de los Acuerdos de 1992. 